\title{
South Korean nursing students' experiences of clinical practice in the newborn nursery and neonatal intensive care unit: A phenomenological study
}

\author{
In Ok $\mathrm{Sim}^{1}$, Ok Yeon $\mathrm{Bae}^{2}$, Tae Hoon $\mathrm{Kim}^{3}$ \\ ${ }^{1}$ Professor, Red Cross College of Nursing, Chung-Ang University, Seoul; ${ }^{2}$ Professor, School of Nursing, Sahmyook Health University, Seoul; \\ ${ }^{3}$ Undergraduate Student, Red Cross College of Nursing, Chung-Ang University, Seoul, Korea
}

Purpose: While clinical practice is crucial for nursing students to acquire the skills needed to provide professional, high-quality nursing care, further studies on improving undergraduate nursing programs are needed to provide a supportive clinical learning environment for student nurses. This study aimed to understand nursing students' clinical experiences in newborn nurseries and neonatal intensive care units and to provide basic data for the establishment of strategies to promote effective clinical education. Methods: Interviews were held with 15 nursing students at J University who had clinical practice experience in the newborn nursery and neonatal intensive care unit. The collected data were analyzed using the phenomenological analysis method developed by Colaizzi (1978). Results: The nursing students' experiences were grouped into four categories: expectations for and anxiety about clinical practice, acquisition of a wide range of knowledge regarding neonatal nursing, challenges faced in clinical practice, and experiencing interpersonal changes. Conclusion: The current neonatal practice nursing education system provides students with positive learning experiences. However, the lack of practice opportunities, insufficient instruction, and the theory-practice gap were identified as major issues hindering students' learning needs. These study results are expected to provide basic data for curriculum development to improve undergraduate nursing education.

Key words: Nursing student; Education, nursing; Infant, newborn; Intensive care, neonatal

\section{Corresponding author In Ok Sim \\ https://orcid.org/0000-0001-8464-2542}

Red Cross College of Nursing, Chung-Ang University,

84 Heukseok-ro, Dongjak-gu, Seoul 06974, Korea

TEL +82-2-820-5988 FAX +82-2-824-7961

E-MAIL hiraly@cau.ac.kr

Received Sep 29, 2020 Revised Nov 25, 2020 Accepted Dec 9, 2020 (a) This is an Open Access article distributed under the terms of the Creative Commons Attribution NonCommercial License (http://creativecommons.org/licenses/by-nc/4.0/) which permits unrestricted noncommercial use, distribution, and reproduction in any medium, provided the original work is properly cited.

\section{INTRODUCTION}

Professional and independent nursing skills are critical for establishing broad theoretical knowledge. The integrated nursing skills gained from clinical experience increase nurses' ability to care for patients and build confidence in critical and independent decision-making in the nursing process. Recently, the nursing education system has introduced measures to strengthen students' capacity by providing curriculum operations to acquire extensive knowledge and hands-on training to build strong clinical skills [1].

Clinical nursing practice can raise the level of competence of undergraduate nursing students; the goal of practice is to apply the nursing process correctly to various cases and to perform the necessary clinical techniques. The clinical environment is crucial for nursing students' practices; therefore, it is necessary to operate clinical training effectively to provide them with professional and high-quality nursing practice in an environment that can strengthen their clinical experiences and skills [2]. However, hospitals forbid students from providing nursing care directly to ensure patient safety and prevent medical accidents. This reduces students' opportunities to learn important clinical skills, as they get the opportunity to practice only minimal nursing skills while observing the per- 
formance of senior nurses.

In particular, the care provided in the newborn room and the neonatal intensive care unit (NICU) should be more specific and delicate than the practices performed in a general ward [3]. The newborn room and the NICU are areas where students' lack of practical nursing experience and skills is particularly relevant [4]. In addition, due to the recent decrease of the birth rate in Korea, cases of clinical treatment for normal and high-risk newborns are insufficient compared to the number of students. Therefore, there are many limitations due to the lack of training places. The inability to obtain sufficient clinical practice for neonates and high-risk neonates makes it difficult for nursing students to reinforce relevant clinical skills [5]. It is important to achieve the purpose of nursing education through effective and diverse educational methods. It is equally crucial to find ways to educate nursing students efficiently considering the safety of patients [6]. As a way to overcome these issues, nursing colleges use a variety of teaching methods such as evidence-based learning, problem-based learning, and simulation-based education [7]. These methods can improve the clinical competence of nursing students by enhancing cognitive thinking abilities, such as critical thinking ability, problem-solving processes, decision-making ability, and clinical reasoning skills [8]. Currently, students' lack of fundamental nursing skills and problem-solving ability in clinical situations are significant challenges [9].

To provide a broad understanding of clinical practice, develop an effective hands-on education system, and build specific strategies for the improvement of the nursing education curriculum, it is necessary to understand nursing students' experiences in the field. In particular, nursing students exposed to unfamiliar clinical situations, such as newborns and high-risk newborns, are expected to have different clinical experiences from those who care for adult patients. To date, although several previous studies on nursing students' clinical experiences in the newborn room or NICU have been conducted $[10,11]$, qualitative research on the perceptions of students with clinical experiences in both the newborn nursery and NICU is very scarce.

Neonatal nursing requires advanced professionalism and ability. It is critical that students acquire academic expertise and have rewarding interpersonal experiences in this field in an adequate clinical environment before they become neonatal nurses in the future. Furthermore, students' lack of insights and experiences prior to clinical placement as registered nurses results in job stress, exhaustion, and low clinical competency [11]. To fill the aforementioned gap in the literature, in the present study, we used the phenomenological method to obtain a better understanding of student nurses' perspectives on the value of clinical learning. Phenomenological analysis is a qualitative research method useful for clarifying the nature and meaning of experiences by analyzing descriptions of human experiences [12].

The purpose of this study was to understand nursing students' clinical experiences at newborn nurseries and NICUs and to provide basic data for the establishment of strategies for effective clinical education.

\section{METHODS}

\section{Research Design}

This study used a qualitative research design using Colaizzi's [13] phenomenological analysis method to obtain an in-depth understanding of the research phenomenon and to describe nursing students' clinical experiences in the newborn nursery and NICU.

\section{Data Collection}

The data were collected among nursing students at the J University School of Nursing. The participants were in their junior or senior year and had completed and experienced clinical practice in both the newborn nursery and NICU from March 2019 to November 2019. The study participants were recruited by advertising on the nursing school website's announcements section. The data collection process included in-depth interviews of the students wherein they shared their experiences and insights about clinical practice. To ensure a comforting and pleasant environment and thus facilitate high-quality communication, the interviews were conducted at the researcher's lab or in other places based on the participants' requests.

This study was intended to investigate students' experiences of clinical practice in the newborn nursery and NICU. Our main research question was:

What was your experience of attending clinical practice as a nursing student in the newborn nursery and NICU? The probing questions were: (1) What(how) have you experienced in the newborn nursery and NICU? (2) What has changed for you before and after clinical practice in the newborn nursery and NICU?

Data collection in qualitative research prioritizes not the sample size, but rather the usefulness of the resource [14]. Despite the lack of stringent guidelines, a qualitative study usually requires 5-8 units of homogenous data and 12-20 units of heterogeneous data [15]. Therefore, 15 nursing students were selected as participants. The interviews took approximately 30 minutes to an hour or more.

\section{Data Analysis}


We analyzed the collected data using Colaizzi's [13] phenomenological analysis method. First, all the participants' statements were reviewed in order to obtain an overall understanding of their experiences and circumstances. Second, significant phrases were extracted and highlighted in the text. Third, the highlighted phrases were reconstructed into significant meanings. Fourth, the significant forms describing experiences were categorized into main themes. Fifth, theme clusters were derived from the main themes. Finally, the collected data were accurately summarized to reflect the key construction of the participants' experiences.

The rigor and trustworthiness of the present study were established using the criteria outlined by Lincoln and Guba [16], including credibility, transferability, dependability, and confirmability. To ensure credibility, we repeatedly listened to the participants' audio-recorded statements and continued to analyze the transcribed data until a sufficient depth of insight was reached to develop the core category. To confirm validity, the results of the final analysis were presented to the study participants to ensure that the results were consistent with the participants' experiences. To ensure transferability, the results were presented to other nursing students (i.e., not the study participants) with clinical practice experience in the same unit, and they confirmed the results. To ensure dependability, the results were analyzed through a peer review process where the researchers gathered to discuss and share opinions on the overall findings and point out any inconsistencies. In order to ensure replicability, we reviewed the relevant literature to gain a deeper understanding and various perspectives on the related research. Finally, to secure neutrality, we tried to avoid bias through reflective insights.

\section{Researchers' Qualifications}

Since the phenomenological analysis of qualitative research requires thorough preparation, we learned about the qualitative research method in advance and conducted a number of qualitative studies. In addition, we attended conferences related to phenomenological qualitative research, and prior learning was conducted before proceeding with this research.

\section{Ethical Considerations}

This study received ethical approval from the Institutional Review Board of Chung-Ang University (1041078-201707-HRSB -144-01). Before the study was conducted, its purpose and methods were explained to the participants, and they had the opportunity to withdraw from the study if they wished to. The data collected from the participants were not used for non-research purposes, and the terms of confidentiality and anonymity were explained to the participants in detail. The study was conducted only after the participants received an adequate verbal explanation of the study's purpose and signed a written consent form. Confidentiality of the participants was guaranteed, and leakage of personal information under any circumstances was prevented. Recorded answers from the interview were used exclusively for the present study, and the participants were assured that no data would be transferred to a third party after the termination of this study. The participants were also informed that all collected data would be stored in the main researcher's personal office for 3 years and would be deleted afterwards.

\section{RESULTS}

\section{Participants' Characteristics}

A total of 15 students (12 females, 3 males) from the School of Nursing at J University were selected as the study participants. The participants were aged 21-26 years. All students were either in their junior year $(n=9)$ or senior year $(n=6)$ and had passed "Clinical Lab: Neonate Nursing", a core course in the Bachelor's degree in nursing. Since the practical component had taken place in five general hospitals, participants had different clinical experiences.

\section{Classification of Nursing Students' Clinical Experiences in Neonatal Units}

Based on the reconstructed data, four main themes and 10 theme clusters were identified. The four main themes were "expectations for and anxiety about clinical practice", "acquisition of a wide range of knowledge regarding neonatal nursing", "challenges faced in clinical practice", and "experiencing interpersonal changes". Below, we discuss the associated theme clusters and significant statements (Table 1).

\section{1) Theme 1: Expectations for and anxiety about clinical practice}

Students had both expectations and anxiety before clinical practice. Positive expectations were due to the excitement of experiencing the nurse's role by observing the general working environment and actual clinical cases and providing nursing care. Anxiety was triggered by feelings of being incompetent and unskillful and by being exposed to unfamiliar areas. The data showed that the students were afraid of making mistakes that might negatively impact the patients and the hospital.

(1) Sub-theme 1: Expectations before clinical practice 
Table 1. Classification of Nursing Students' Clinical Experiences in Neonatal Units

\begin{tabular}{|c|c|c|}
\hline Theme & Sub-theme & Significant statements \\
\hline \multirow[t]{2}{*}{$\begin{array}{l}\text { Expectations for and } \\
\text { anxiety about clinical } \\
\text { practice }\end{array}$} & $\begin{array}{l}\text { Expectations before } \\
\text { clinical practice }\end{array}$ & $\begin{array}{l}\text { - Looking forward to experiencing the nursing care and observing actual clinical cases } \\
\text { - Looking forward to providing daily nursing care for infants, learning about the } \\
\text { nurse's role, and observing the procedure of infants being transferred from the } \\
\text { delivery room to the neonatal unit }\end{array}$ \\
\hline & $\begin{array}{l}\text { Fear of an unfamiliar } \\
\text { hospital environment } \\
\text { and making mistakes }\end{array}$ & - Being afraid of making a mistake that could be detrimental to an infant \\
\hline \multirow[t]{2}{*}{$\begin{array}{l}\text { Acquisition of a wide } \\
\text { range of knowledge } \\
\text { regarding neonatal } \\
\text { nursing }\end{array}$} & $\begin{array}{l}\text { Understanding the } \\
\text { characteristics of } \\
\text { neonatal nursing care }\end{array}$ & $\begin{array}{l}\text { - Learning the importance of preventive nursing care } \\
\text { - Understanding comprehensive nursing care } \\
\cdot \text { - Monitoring vital signs of infants } \\
\cdot \text { Realizing the importance of assessment skills as a neonatal unit nurse }\end{array}$ \\
\hline & $\begin{array}{l}\text { Observing various } \\
\text { clinical cases }\end{array}$ & $\begin{array}{l}\text { Clear comprehension of diagnosis and treatment after observing the whole process } \\
\text { - Observing a rare clinical case that provides a good reference for the future }\end{array}$ \\
\hline \multirow[t]{3}{*}{$\begin{array}{l}\text { Challenges faced in } \\
\text { clinical practice }\end{array}$} & $\begin{array}{l}\text { Exposure to a poor } \\
\text { clinical environment }\end{array}$ & $\begin{array}{l}\text { - Feeling bored due to lack of practice with special medical treatment such as } \\
\text { phototherapy and lack of high-risk infant cases } \\
\text { - Difficulty in providing quality nursing care in small working spaces } \\
\text { - Lack of equipment to monitor vital signs as well as human resources } \\
\text { - Limited number of infant admissions in the hospital }\end{array}$ \\
\hline & $\begin{array}{l}\text { Staff nurses' } \\
\text { indifference }\end{array}$ & $\begin{array}{l}\text { - No guidance provided } \\
\text { - Limited or no practice allowed as a nursing student }\end{array}$ \\
\hline & $\begin{array}{l}\text { Communication } \\
\text { difficulties with } \\
\text { parents }\end{array}$ & $\begin{array}{l}\text { - Parents giving frustrated looks when their questions are unresolved } \\
\text { - Lack of opportunity to observe and communicate with parents during visiting time } \\
\text { - Facing difficulty in providing emotional support to crying parents }\end{array}$ \\
\hline \multirow[t]{3}{*}{$\begin{array}{l}\text { Experiencing } \\
\text { interpersonal changes }\end{array}$} & $\begin{array}{l}\text { Being affectionate } \\
\text { towards infants }\end{array}$ & $\begin{array}{l}\text { - Infants are adorable } \\
\cdot \text { Feeling a serious sense of responsibility when holding a baby }\end{array}$ \\
\hline & $\begin{array}{l}\text { Feeling gratitude } \\
\text { towards parents }\end{array}$ & $\begin{array}{l}\text { - Understanding the role of parents } \\
\text { - Having thoughts about how hard it must have been for my parents to raise me } \\
\text { - Being thankful to parents for my good health }\end{array}$ \\
\hline & $\begin{array}{l}\text { Overview of becoming } \\
\text { a neonatal unit nurse }\end{array}$ & $\begin{array}{l}\text { - Not a good place for the first job of unexperienced nurses } \\
\text { - Feeling skeptical regarding whether nursing skills learned at the newborn nursery } \\
\text { can be applied to other departments }\end{array}$ \\
\hline
\end{tabular}

In general, students looked forward to learning and carrying out nursing care in real-life situations. When assigned to neonatal units in clinical practice, the participants were specifically interested in neonatal nursing.

I was ready to apply the skills to perform well in the clinical practice and looking forward to seeing various medical cases in real life and how nursing care should be carried out. (Participant 3)

I was full of excitement to take care of the babies. I was also interested in how nursing care is provided in the neonatal unit and the procedure of newborns being transferred from the delivery room to the neonatal unit. (Participant 10)

(2) Sub-theme 2: Fear of an unfamiliar hospital environment and making mistakes

The participants were also anxious about carrying out clin- ical practice in the neonatal unit, as they were not familiar with that unit or with the nursing care provided therein. They were particularly afraid of making a mistake that could adversely affect infants' condition.

Knowing that the setting and the nursing processes in the neonatal unit are different, I was worried about making mistakes that could harm the infants. (Participant 1)

I was afraid that I might accidently drop the infant while feeding. (Participant 6)

\section{2) Theme 2: Acquisition of a wide range of knowledge regarding neonatal nursing}

Clinical practice allows students to broaden their spectrum of nursing knowledge and to better understand the role of nurses by providing nursing care to real patients. Accordingly, through clinical practice, the participants were able to understand the specific characteristics of nursing care provided 
in neonatal units and expressed positive views regarding their privilege of learning through observing a variety of clinical conditions.

(1) Sub-theme 1: Understanding the characteristics of neonatal nursing care

The participants stated that "preventive care" and monitoring of clinical status were strict requirements in neonatal units, since neonates are vulnerable to pathogenic bacteria and sensitive to changes in the environment.

Compared to other units, I learned that the act of preventive nursing care, including hand hygiene and use of masks, is crucial for infant care. (Participant 1)

I noticed that comprehensive nursing care is provided in neonatal units because newborns cannot do anything on their own without somebody's care. (Participant 8)

Monitoring the vital signs of neonates is a critical process in nursing care, because a small change in a clinical indicator may cause a potential emergency situation. (Participant 11)

I realized that excellent physical assessment skills are required for nurses in the neonatal unit. In one particular instance, after finding dimples on a newborn's body, the newborn was immediately sent for further examination. A careful physical assessment allows for early recognition of an existing problem, thereby preventing potential physical harm or abnormalities. (Participant 12)

\section{(2) Sub-theme 2: Observing various clinical cases}

Most participants observed various conditions that they had learned about in class through textbooks and could identify the clinical status of the disease, medication usage, and the nursing process of various clinical cases.

Learning by observing is one of the greatest advantages of clinical practice. At first, I was not clear how respiratory disease syndrome in newborns was diagnosed and treated so quickly. I saw how the nurses and other medical staff identified abnormalities in vital signs and physical assessment, and made quick decisions to proceed to further examinations. In one case, when an asymmetrical consolidation was found on an X-ray, the surfactant was prepared for a possible immediate injection. After observing the whole process, what I learned through textbooks became clear, and I was able to absorb the knowledge. (Participant 5)

I was lucky enough to see a patient with cleft palate, which is a rare phenomenon nowadays, and it was something I had read about only in textbooks. This experience would be a good reference in the future. (Participant 11)

\section{3) Theme 3: Challenges faced in clinical practice}

The participants also shared the challenges they had faced during clinical practice. Since the students were not registered nurses yet, they had only limited clinical practice opportunities. For instance, the students felt that their clinical education was inadequate when they observed the staff nurses' preoccupation with their responsibilities. Students also perceived communication barriers with the newborns' parents. After diligent observation, the participants could identify existing problems in the neonatal units regarding the poor clinical environment.

(1) Sub-theme 1: Exposure to a poor clinical environment The participants shared the problems they had experienced in terms of the nursing care environment.

The hospital I was assigned to for clinical practice did not own any special medical equipment for treatments like phototherapy, which I consider to be essential for premature infants. Plus, the hospital no longer accepted high-risk neonates, so there was nothing to learn. (Participant 14)

Both the newborn nursery and the intensive care unit did not have enough monitoring screens or medical staff, and I felt that the lack of resources was problematic for providing adequate nursing care for everybody. (Participant 5)

The limited space of the intensive care unit seemed to have a negative influence on the quality of nursing care. A small working space can be stressful to nurses and may result in poor nursing care attitudes/habits, such as indifference to infants' crying. (Participant 2)

There seems to be a limited number of newborns that the intensive care unit can accept. In one instance, when high-risk triplets were born, an infant whose discharge date was close got temporarily transferred to the newborn nursery. I think this newborn certainly deserved to stay in the intensive care unit, since high-risk infants need close observation until the day of discharge. I feel extra beds are needed to accommodate such babies. (Participant 11)

\section{(2) Sub-theme 2: Staff nurses' indifference}

One of the main problems that the students experienced was the staff nurses' indifference. The participants were often left alone and not provided with any guidance as the staff nurses remained preoccupied with their duties. 
The nurses were extremely busy with their work, so the students were not provided any guidance. All I did was just sit there and watch the babies. Clinical practice was a means to simply pass time rather than learning something new. (Participant 9)

At first, the nurse told me to watch the babies and report any abnormal clinical status. I stayed right beside the incubator doing nothing for 3 hours. Although I understand the busy nature of nurses' jobs, I wish there was someone who could pay attention to nursing students. (Participant 1)

I was slightly disappointed that there is nothing nursing students could do in practice. Even though we are not registered nurses, I wish there was someone who could explain certain parts of nursing care, such as the equipment used or medication injected. It is not easy for students to ask the busy nurses about every single detail. (Participant 12)

(3) Sub-theme 3: Communication difficulties with parents

The students also commented on the limited opportunities provided to observe and communicate with infants' parents due to a safety policy that limits the number of people present in the ward for infection prevention and control. Some nursing students were not allowed to be present in the unit during visiting hours.

We were asked to stay in the staff lounge during visiting hours. The purpose of this was to reduce the risk of infection by limiting the number of people present in the unit. Thus, I could neither observe the parents' behavior and responses, nor build a rapport with them. There was literally nothing we could do. (Participant 12)

I had a parent who asked me something about the incubator, but I couldn't answer the question since I did not know the details. The parent stared at me, giving me an odd look, and I have felt uncomfortable communicating with parents since then. (Participant 15)

I had no idea of how to provide emotional support to a parent crying while watching her child hardly breathing, with multiple IV lines injected. I realized the need to additionally study communication techniques. (Participant 13)

\section{4) Theme 4: Experiencing interpersonal changes}

The final theme describes the interpersonal changes that the students experienced after clinical practice. These included changes in the participants' thoughts and views towards their own parents, infants, and nurses.

(1) Sub-theme 1: Being affectionate towards infants
Providing nursing care to infants was a novel experience for most nursing students. As they took care of the infants, they became attached to them.

Before the clinical practice, the first thing that came to my mind when I thought of babies was them crying loudly in public places; I sometimes got annoyed by the sound and wanted to stay away from them. As I got to see and touch them, I found that the babies were so small, soft, and adorable. Now I look at babies with joy and can spend a long hour of clinical practice looking at those endearing faces. (Participant 5)

The feeling of actually carrying a baby with my arms, giving skin-to-skin warmth was so different from what I had thought about newborns when simply observing them. I developed attachment and could feel a great sense of responsibility and protection toward the baby. This experience has also changed my beliefs about childless marriages. (Participant 9)

(2) Sub-theme 2: Feeling gratitude towards parents

The experience of providing nursing care for newborns helped the participants develop a sense of gratitude towards their parents, since the students were able to better understand the journey of raising a child.

Although I am a nursing student, I could experience what parenting is. After the practice, I learned to be thankful to my parents. (Participant 8)

Feeding, changing diapers, soothing crying babies $\cdots$ none of these are easy tasks, and I could feel how hard it must have been for my parents to bring me up and run the household at the same time. (Participant 13)

While it is such a heartbreaking moment to see high-risk infants in pain, I am grateful for my parents for raising me to be a strong and healthy person. (Participant 2)

(3) Sub-theme 3: Overview of becoming a neonatal unit nurse The study participants' thoughts on working as nurses in the newborn nursery and NICU were categorized into two perspectives: positive and negative. The participants with a positive view emphasized that nursing critically ill newborns is a unique area of specialized nursing. In contrast, the participants with negative views indicated that the NICU is a place where intensive nursing skills can be learned and experienced; however, a neonatal unit nurse needs simple nursing and knowledge, and working in the neonatal unit is not preferable as a path towards continuous professional growth. 
- Positive views

Based on the experience, I consider nursing in the newborn nursery to be the most ideal career. The nursing care itself and verbal handovers were relatively simple compared to other units. Unlike the busy atmosphere in other departments, the nursery seems to be less preoccupied and more relaxed; there were few newborns each nurse was assigned to care for. More importantly, looking at those adorable infants made my day. I would like to work at a place where a certain level of leisure and personal happiness is guaranteed. (Participant 2)

Despite the worries, my clinical practice at the infant unit was full of new experiences. I observed various cases and nursing care provided at the nursery and intensive care unit. The newborn nursery was the first place where students could actually provide nursing care to patients. I learned how to feed and pacify babies, monitor their clinical status, and change their diapers. As a future nurse, I would like to refine my nursing skills and become a professional by working in the nursery room. (Participant 14)

- Negative views

I personally think the newborn nursery is not a good place for new graduate nurses to build their professional skills. There is little opportunity to learn to handle emergency situations, and all tasks are very routine-based. The duties might be convenient, but there are limited opportunities to learn the nursing skills required to become a professional nurse. (Participant 3)

I am not sure how the nursing skills learned and practiced at the newborn nursery can be applied to other places and situations. It is just better to leave it behind as a good clinical experience. (Participant 11)

\section{DISCUSSION}

In the present study, using Colaizzi's [13] phenomenological analysis method, we categorized nursing students' clinical practice experiences into four main themes and 10 sub-themes based on the collected significant statements. The students' responses included various insights and experiences and showed some positive and negative aspects of the current clinical education system.

\section{Theme 1: Expectations for and Anxiety about Clinical Practice}

In general, the participants had expectations for clinical practice; however, there were various complaints and anxiety about clinical practice as well. Nursing students who have completed 2 to 3 years of theoretical nursing education and simulation training at the nursing college are expected to be able to practice accurate and repetitive nursing skills appropriate to theory in clinical practice in hospitals. In line with the results reported by Esmaeili et al. [17], the meaning attributed to clinical practice by these students aligns with the research findings, as they expected the integrated ability of theory and practice to be strengthened as part of effective clinical education. Through active clinical practice, students are expected to learn from real situations and develop problem-solving skills and critical thinking skills to gain the competence of professional nurses [18].

However, even with these positive expectations, the students experienced anxiety during their training in the newborn nursery and NICU. Specifically, they experienced fear and anxiety about the numerous instruments used to treat high-risk newborns and the practice of professional nursing. The participants felt anxious and apprehensive when they first encountered a special environment equipped to provide care to newborn babies or small children. In the newborn nursery, students experienced the most fear regarding feeding the babies, accidentally dropping a newborn baby when changing a diaper, anxiety about injuries, and the possibility that these mistakes can cause life-threatening damage.

Since nursing college students are not registered nurses, they are less likely to be legally protected from this type of medical accidents, so their fears doubled when thinking about facing legal issues. In order to avoid such catastrophic events and reduce fear, it is necessary to instruct nursing students on the proper posture and to teach them how to hold newborn babies in a simulation laboratory prior to clinical practice. Our results also suggest that careful supervision of nurses should be ensured in the practice process.

\section{Theme 2: Acquisition of a Wide Range of Knowledge Regarding Neonatal Nursing}

One of the main advantages of clinical practice is that students can acquire extensive medical knowledge and understanding of clinical conditions or nursing by observing real patients. Upon experiencing practice in high-risk neonatal units, the students who participated in this study found that monitoring vital signs, neonates' physical condition, and preventive care needed more attention, particularly in neonatal units where vulnerable patients were being treated. This is consistent with how NICU patients have been described as requiring complex treatments and a high overall level of nursing resources [19]. In addition, enhanced attention to clinical practice can contribute to nursing students' ability to provide 
better nursing services in other departments in the future. Students also described the benefits of having clinical experience in neonatal care where they were able to observe a variety of clinical cases specific to infants, such as cleft palate. In addition, critical reasoning techniques can be used to identify systematic problems in the NICU, highlighting the effectiveness of clinical education. The problems faced by students included a small workspace, a lack of resources (including equipment and personnel), and the limited capacity for high-risk neonatal admissions in hospitals.

\section{Theme 3: Challenges Faced in Clinical Practice}

The results of the interviews highlighted some challenges in clinical education. First, as nursing students, participants had limited opportunities to provide nursing care, which was one of the main issues hindering their learning needs. According to Cho and Kwon [20], student nurses have limited opportunities to provide nursing care due to patients' increasing demand for high-quality medical services. This trend has led to a focus on "observatory learning" in education, rather than on practical learning [21]. Bang et al. [22] found that students showed improvements in nursing skills and self-confidence by conducting actual nursing intervention, such as oral administration of drugs, intravenous injections, infusion solution preparation, infusion/syringe pump usage, and preand post-operative nursing care. As there are currently no educational methods other than simulation practice for pediatric or neonatal nursing [4], further research and development of clinical education programs is necessary to enhance the role and quality of student nurses.

Second, nursing students often perceived a lack of instruction from their preceptors. A number of students commented about their preceptors' indifference. In the backdrop of the routine in the newborn nursery and the preoccupations of staff in the NICU, the students noted a lack of guidance and responsibilities provided to them. The only task the students were assigned was simply monitoring the infants. Therefore, the preceptorship might be stressful in that the "students may feel alone in their placements with no one they can turn for help" [23]. Therefore, staff nurses and supervisors should provide instructions to nursing students so that they are "encouraged to recognize the influence they exert over their own clinical learning environment, and to proactively work to create the kind of environment which will best meet their learning needs" [24].

Third, the students commented on the inequity of clinical learning education due to disparities in clinical practice settings of hospitals. Many hospitals cannot provide an educational environment suited for clinical learning [25]. With the recent closure of many delivery rooms and newborn care units in Korean hospitals, some students were even assigned to preschools or orphanages for clinical practice [26]. Meanwhile, some general hospitals do not possess adequate medical equipment for treating premature newborns such as a phototherapy radiometer, which limits students' ability to acquire a broad spectrum of nursing skills. Moreover, most participants were not given the opportunity to communicate with infants' parents to reduce the risk of infection, and some faced communication challenges. Professors and hospitals should determine the learning requirements currently missing in clinical practice and find ways to meet these needs.

\section{Theme 4: Experiencing Interpersonal Changes}

Along with the academic perspective of clinical education, both positive and negative aspects of the interpersonal changes experienced by students during neonatal clinical practice should be taken into account. The participants treated their young patients with affection and built a rapport with them. Even those with no particular feelings about infants in general were able to form an attachment and feel responsible for providing quality nursing care. Feeling gratitude towards their own parents was also a positive sign, considering that one of the goals of education is to nurture students' moral development and interpersonal maturity.

Clinical practice in the neonatal unit also gave students negative impressions in terms of nursing professionalism-particularly in the newborn nursery. Students reported that this unique area of newborn nursing was not the best option to start as a new graduate nurse, and that the nursing tasks or skills were not quite applicable to other areas. Instead, a more attractive option for students was becoming a nurse in a NICU, where advanced nursing skills and the same nursing skills provided in the nursery room can be performed simultaneously. It is important that students are provided with neonatal health education focused on newborns in the nursing room, and they also need to be motivated to understand the value of nursing care for newborns.

The principal limitation of this study is that the results only partially confirmed the suitability of nursing students' clinical practice environment and newborn clinical cases. Given the recent decrease in the pregnancy and birth rate in South Korea, this study's results reflect students' clinical practice experiences with limited clinical cases and aspects of the clinical environment that students can observe. Thus, it is difficult to interpret these findings as objective descriptors generalizable to neonatal practice experience, and further research is therefore needed to explain students' diverse experiences and differences in neonatal clinical practices experienced by nursing students at other institutions. 


\section{CONCLUSION}

The current nursing education system clearly provides many positive learning experiences to students. Although the participants in this study might have experienced anxiety at the beginning of their clinical practice, they soon adapted to the environment and fulfilled their learning experience by observing various nursing interventions and attempting to improve their critical reasoning skills. Clinical experience in neonatal units was also found to contribute to interpersonal changes and building one's character.

The results of the present study may be used as a reference for improvements in undergraduate nursing education. Regarding ways to ensure a comprehensive education program, first, clinical practice should focus on students' participation in nursing intervention to help build their competence and confidence. The educational institution must provide further opportunities to students to receive exposure to a variety of clinical conditions and to refine their nursing skills, as it is "important for them to play an assertive role in ensuring their own best learning" [23]. Second, hospitals should construct a system or manual regarding clinical education for student nurses. Such educational instruction guides may include creating a welcoming and supporting atmosphere, allocating an exclusive (or semi-exclusive), suitable, and capable preceptor during students' preceptorship, assigning basic nursing tasks, and ensuring that students are debriefed regarding their performance of nursing skills. Such changes will allow students to develop their critical reasoning skills by sharing and receiving feedback regarding the nursing process.

\section{Conflict of interest}

No existing or potential conflict of interest relevant to this article was reported.

\section{Data availability}

Please contact the corresponding author for data availability.

\section{REFERENCES}

1. Ding X, Wang L, Sun J, Li D, Zheng B, He S, et al. Effectiveness of empathy clinical education for children's nursing students: A quasi-experimental study. Nurse Education Today. 2020;85:104260. https://doi.org/10.1016/j.nedt.2019.104260

2. Lee HJ. Convergence study on nursing students' stress and satisfaction with clinical practice. Journal of the Korea Convergence Society. 2016;7(4):75-83.

https://doi.org/10.15207/JKCS.2016.7.4.075
3. Kwon IS. An analysis on clinical education of pediatric nursing. Child Health Nursing Research. 2002;8(3):334-356.

4. Shin HS, Shim KK. Nursing student's experiences on pediatric nursing simulation practice. Journal of East-West Nursing Research. 2010;16(2):147-155.

5. Lee C. Seeking a better system for the better neonatal care in Korea. Journal of the Korean Medical Association. 2006;49(11):1009-1016. https://doi.org/10.5124/jkma.2006.49.11.1009

6. Christiansen A, Prescott T, Ball J. Learning in action: Developing safety improvement capabilities through action learning. Nurse Education Today. 2014;34(2):243-247. https://doi.org/10.1016/j.nedt.2013.07.008

7. Harris MA. Simulation-enhanced pediatric clinical orientation. Journal of Nursing Education. 2011;50(8):461-465. https://doi.org/10.3928/01484834-20110429-05

8. Blum CA, Borglund S, Parcells D. High-fidelity nursing simulation: Impact on student self-confidence and clinical competence. International Journal of Nursing Education Scholarship. 2010; 7(1):Article 18. https:// doi.org/10.2202/1548-923X.2035

9. Kwon IS, Seo YM. Nursing students' needs for clinical nursing education. Journal of Korean Academic Society of Nursing Education. 2012;18(1):25-33.

https://doi.org/10.5977/jkasne.2012.18.1.025

10. Choi EA, Lee KE, Lee YE. Nursing students' practice experience in neonatal intensive care units. Child Health Nursing Research. 2015;21(3):261-271.

https://doi.org/10.4094/chnr.2015.21.3.261

11. Baek KS. Experiences of newborn nursery care practice among the male nursing students. Journal of Qualitative Research. 2006;7(1): 25-37.

12. Kim NH, Lee EJ, Kwak SY, Park MR. A phenomenological study on the experiences of parenting burden of working mother with young children in Korea. Korean Journal of Women Health of Nursing. 2013;19(3):188-200.

https://doi.org/10.4069/kjwhn.2013.19.3.188

13. Colaizzi PF. Psychological research as the phenomenologist views it. In: Valle RS, King M, editors. Existential-phenomenological alternatives for psychology. New York: Oxford University Press; 1978. p. 6.

14. Lopez V, Whitehead D. Sampling data and data collection in qualitative research. In: Schneider Z, Whitehead D, LoBiondi-Wood G, Haber J, editors. Nursing and midwifery research: Methods and critical appraisal for evidence-based practice. 4th ed. London: Elsevier Health Sciences; 2013. p. 124-140.

15. Kuzel AJ. Sampling in qualitative inquiry. In: Crabtree BF, Miller WL, editors. Doing qualitative research. 2nd ed. Los Angeles, CA: Sage Publications; 1999. p. 33-45.

16. Lincoln YS, Guba EG. Epistemological and methodological bases of naturalistic inquiry. Educational Communication and Technology. 1982;30(4):233-252. 
17. Esmaeili M, Cheraghi MA, Salsali M, Ghiyasvandian S. Nursing students' expectations regarding effective clinical education: A qualitative study. International Journal of Nursing Practice. 2013; 20(5):460-467. https://doi.org/10.1111/ijn.12159

18. Rajeswaran L. Clinical experiences of nursing students at a selected institute of health sciences in Botswana. Health Science Journal. 2016;10(6):1-6. https://doi.org/10.21767/1791-809X.1000471

19. Rogowski JA, Staiger DO, Patrick TE, Horbar JD, Kenny MJ, Lake ET. Nurse staffing in neonatal intensive care units in the United States. Research in Nursing and Health. 2015;38(5):333-341. https://doi.org/10.1002/nur.21674

20. Cho MH, Kwon IS. A study on the clinical practice experiences on nursing activities of nursing students. Journal of Korean Academic Society of Nursing Education. 2007;13(2):143-154.

21. Yang JJ. An analysis of nursing outcomes and interventions according to nursing diagnoses for inpatients with brain hemorrhages by undergraduate nursing students. Chonnam Journal of Nursing Science. 2007;12(1):1-13

22. Bang KS, Chae SM, Yu JY, Song MK, Lee JH. Comparison of pro- fessional self-concept, clinical nursing competence, and practicum satisfaction between nursing students with and without pediatric nursing clinical preceptorship. Journal of Korean Academic Society of Nursing Education. 2013;19(3):396-404

https://doi.org/10.5977/jkasne.2013.19.3.396

23. Yonge $\mathrm{O}$, Myrick F, Haase M. Student nurse stress in the preceptorship experience. Nurse Educator. 2002;27(2):84-88.

https://doi.org/10.1097/00006223-200203000-00012

24. Dunn SV, Hansford B. Undergraduate nursing students' perceptions of their clinical learning environment. Journal of Advanced Nursing. 1997;25(6):1299-1306. https://doi.org/10.1046/j.1365-2648.1997.19970251299.x

25. Salamonson Y, Everett B, Halcomb E, Hutchinson M, Jackson D, Mannix J, et al. Unravelling the complexities of nursing students' feedback on the clinical learning environment: A mixed methods approach. Nurse Education Today. 2015;35(1):206-211. https://doi.org/10.1016/j.nedt.2014.08.005

26. Kim JY, An MS, Park HJ. Effectiveness of infant care competence according to pediatric nursing practice at school. Korean ParentChild Health Journal. 2012;15(1):14-19. 